\title{
New skulls of the basal sauropodomorph Plateosaurus trossingensis from Frick, Switzerland: Is there more than one species?
}

\author{
Jens N. Lallensack, Elżbieta M. Teschner, Ben Pabst, and P. Martin Sander \\ Acta Palaeontologica Polonica 66 (1), 2021: 1-28 doi:https://doi.org/10.4202/app.00804.2020
}

The Triassic basal sauropodomorph Plateosaurus trossingensis is well-known from mass accumulations at the German localities of Trossingen and Halberstadt and the Swiss locality of Frick, and is significant especially regarding its taphonomy and proposed developmental plasticity. These implications, however, rely on the assumption that this material derives from a single species, which has been questioned. Here we describe new skull material from Frick including eight complete and six partial skulls, more than doubling the number of known skulls of $P$. trossingensis. This exceptional sample size allows for gaining a deeper understanding of variability that may occur in a single species. The new material includes the first known juvenile skulls of Plateosaurus, allowing for detecting ontogenetic changes. An attempt is made to distinguish between variability caused by taphonomic plastic deformation and intraspecific variability. Plastic deformation may shorten, but not widen bones. A number of characters commonly included in phylogenetic analyses of basal sauropodomorphs are shown to be variable within $P$. trossingensis, and possibly require re-evaluation. Although $P$. trossingensis skulls are highly variable, many of the variable characters include intermediate character states and therefore are continuous. No groupings based on skull features, locality, or stratigraphy are apparent. Consequently, the analyzed skull material from the bonebeds of Frick, Trossingen, and Halberstadt bears no evidence for the presence of more than one species.

Key words: Dinosauria, Sauropodomorpha, Plateosaurus , ontogeny, intraspecific variability, preservation, skull anatomy, Triassic, Switzerland.

Jens. N. Lallensack [info@ dinospuren.de], Section Paleontology, Institute of Geoscience, University of Bonn, Nussallee 8, 53115 Bonn, Germany; School of Natural Sciences and Psychology, Liverpool John Moores University, James Parsons Building, Bryon Street, Liverpool L3 3AF, UK. Elżbieta M. Teschner [eteschner@uni.opole.pl ], Section Paleontology, Institute of Geoscience, University of Bonn, Nussallee 8, 53115 Bonn, Germany; Institute of Biology, University of Opole, Oleska 22, 45-052, Opole, Poland. Ben Pabst [benpabst@bluewin.ch], Sauriermuseum Aathal, Zürichstrasse 69, 8607 Aathal-Seegräben, Switzerland. P. Martin Sander [martin.sander@uni-bonn.de], Section Paleontology, Institute of Geoscience, University of Bonn, Nussallee 8, 53115 Bonn, Germany; Dinosaur Institute, Natural History Museum of Los Angeles County, 
900 Exposition Boulevard, Los Angeles, CA 90007, USA.

This is an open-access article distributed under the terms of the Creative Commons Attribution License (for details please see creativecommons.org), which permits unrestricted use, distribution, and reproduction in any medium, provided the original author and source are credited.

\footnotetext{
Fofif Full text $(5,007.7 \mathrm{kB})$

Far) Supplementary file $(189.6 \mathrm{kB})$
} 